\title{
Effects of lifestyle education program for type 2 diabetes patients in clinics: a cluster randomized controlled trial
}

\author{
Misa Adachi ${ }^{1 \dagger}$, Kazue Yamaoka ${ }^{2 *}$, Mariko Watanabe ${ }^{3 \dagger}$, Masako Nishikawa ${ }^{4 \dagger}$, Itsuro Kobayashi ${ }^{5 \dagger}$, Eisuke Hida ${ }^{6 \dagger}$ \\ and Toshiro Tango ${ }^{6 \dagger}$
}

\begin{abstract}
Background: The prevalence of type 2 diabetes is rising worldwide, as has been the global mean fasting plasma glucose level. This study aimed to evaluate the effectiveness of a structured individual-based lifestyle education (SILE) program to reduce the hemoglobin $\mathrm{A} 1 \mathrm{c}\left(\mathrm{HbA}_{1 \mathrm{c}}\right)$ level in type 2 diabetes patients delivered by registered dietitians in primary care clinical settings.

Methods: This was a 6-month prospective cluster randomized controlled trial in a primary care setting with randomization at the practice level. Twenty general practitioners in 20 clinics in Kanagawa prefecture, Japan, were involved. 193 adults (51\% men, mean age 61.3 years) with type 2 diabetes and $\mathrm{HbA}_{1 c} \geq 6.5 \%$ who received treatment in medical clinics were the participants. A SILE program was implemented through 4 sessions with trained registered dietitians during the 6-month study period. Results were compared with those of a control group who received usual care. The primary endpoint was the change in $\mathrm{HbA}_{1 c}$ levels at 6 months from baseline. Secondary endpoints were the changes at 6 months from baseline in fasting plasma glucose, lipid profile, blood pressure, BMI, energy, and nutrient intakes (whole day and each meal). Intention-to-treat analysis was conducted. Mixed-effects linear models were used to examine the effects of the treatment.

Results: The mean change at 6 months from baseline in $\mathrm{HbA}_{1 \mathrm{c}}$ was a $0.7 \%$ decrease in the intervention group $(n=100)$ and a $0.2 \%$ decrease in the control group $(n=93)$ (difference $-0.5 \%, 95 \% \mathrm{Cl}:-0.2 \%$ to $-0.8 \%, p=0.004)$. After adjusting for baseline values and other factors, the difference was still significant ( $p=0.003 \sim 0.011)$. The intervention group had a significantly greater decrease in mean energy intake at dinner compared with the control group and a greater increase in mean vegetable intake for the whole day, breakfast, and lunch as shown in crude and adjusted models. A tendency toward improvement was observed in the other secondary endpoints but the improvement was not statistically significant. These results were confirmed by several sensitivity analyses.
\end{abstract}

Conclusions: The SILE program that was provided in primary care settings for patients with type 2 diabetes resulted in greater improvement in $\mathrm{HbA}_{1 \mathrm{c}}$ levels than usual diabetes care and education.

Trial registration: UMIN000004049

Keywords: Diabetes type 2, Lifestyle education, Cluster randomized trial, Dietary habit, Food frequency questionnaire

\footnotetext{
*Correspondence: kazue@med.teikyo-u.ac.jp

${ }^{\dagger}$ Equal contributors

${ }^{2}$ Teikyo University, Graduate School of Public Health, 2-11-1 Kaga, Itabashi-ku,

Tokyo 173-8605, Japan

Full list of author information is available at the end of the article
} 


\section{Background}

The prevalence of type 2 diabetes is rising worldwide, as has been the global mean fasting plasma glucose (FPG) level [1]. Type 2 diabetes is associated with serious complications such as blindness and renal failure, as well as an increased risk of cardiovascular disease [2]. Type 2 diabetes is responsible for a disproportionate use of health service resources, and its increased prevalence presents a serious problem from the viewpoint of medical economics. In Japan, approximately 8.9 million people are estimated to have diabetes based on a hemoglobin A1c $\left(\mathrm{HbA}_{1 \mathrm{c}}\right)$ level of $6.5 \%$ (NGSP) or over or receiving treatment for type 2 diabetes [3]. Lifestyle modification is the cornerstone of treatment for people with type 2 diabetes. Little evidence of benefit exists for nutritional education in patients with type 2 diabetes in clinics in community medicine settings. Lack of a useful tool to assess dietary intake and difficulty in continuous management of a patient's lifestyle may be related to this.

Meta-analyses of randomized controlled trials (RCTs) have shown that lifestyle interventions improved glycemic control with type 2 diabetes patients [4]. Although several types of lifestyle education programs have been proposed, reports of their effectiveness in Asian populations, including Japanese populations, have been scant $[5,6]$. Considering that a frequent feature of type 2 diabetes in Japan is not obesity, dietary education that focuses on the pattern of eating to improve the $\mathrm{HbA}_{1 \mathrm{c}}$ level by controlling the postprandial rise in plasma glucose and by improving the fasting plasma glucose level is important. Namely, modifying energy intake at dinner and increasing vegetable intake at breakfast and lunch should be effective. The rationale for this strategy is based on the following: 1) proper energy intake at dinner is important since night-time activity is less than day-time activity considering circadian rhythms [7]; 2) a meal with increased dietary fiber can control the postprandial rise in the plasma glucose level and contribute to the improvement in $\mathrm{HbA}_{1 \mathrm{c}}$ [8]; and 3) to increase vegetable intake at breakfast and lunch is required because vegetable intake at these meals is usually less than at dinner. Therefore, to conduct effective dietary education, an appropriate assessment of nutritional intake at each meal is important.

A food frequency questionnaire (FFQ) is a feasible method for this purpose, and we developed a FFQ consisting of a list of 82 foods (FFQW82) [9]. Using the FFQW82, we have recently developed a structured individual-based lifestyle education (SILE) program to be used in clinics that aims to modify dietary intake at breakfast, lunch, and dinner and that is focused on behavior assessment, goalsetting, problem-solving, and provision of tailored information from registered dietitians. The main current recommendations for individuals with diabetes by the
Japan Diabetes Society (JDS) [10] related to energy intake are calculated using the ideal body weight and three levels of physical activity. The proportion of total energy intake from carbohydrate is recommended to be $50 \sim 60 \%$ and from total fat less than $25 \%$, from saturated fatty acid less than $7 \%$, and from polyunsaturated fatty acid less than $10 \%$. Intakes of protein, fiber, and salt are recommended to be $1.0 \sim 1.2 \mathrm{~g} / \mathrm{kg} /$ day, $20 \sim$ $25 \mathrm{~g} /$ day, and less than $10 \mathrm{~g} /$ day, respectively. Our SILE program basically follows the guidelines of the JDS with the additional recommendation to reduce energy intake at dinner and increase vegetable intake at breakfast and lunch, which should be a more practical strategy than the JDS recommendations.

The aim of this study was to examine the effect of lifestyle education using the SILE program provided by registered dietitians for type 2 diabetes patients in primary care clinics by assessing changes in $\mathrm{HbA}_{1 \mathrm{c}}$ levels, other clinical data and dietary intakes. Results will provide useful information for not only Japanese type 2 diabetes patients but also for type 2 diabetes patients in other Asian countries and for patients in Western countries who have already modified their dietary intake to some extent, although still insufficiently, or who have failed with regard to weight control in many instances.

\section{Methods}

\section{Study design}

This was a 6-month cluster randomized controlled trial with two intervention arms performed between September 2007 and June 2011 inclusive at clinics in Kanagawa prefecture, Japan. Details of the study design and calculation of the sample size were published previously [11], with only a brief description shown below. The study was approved by the Medical Ethical Committee of the National Institute of Public Health in Japan in 2006 (NO. NIPH-IBRA \#06005).

\section{Participants}

Volunteer general practitioners who agreed with our study purposes and procedures were recruited. We randomly assigned in turn a general practitioner representing a primary care clinic to either the intervention group (IG) or control group (CG) with the use of a randomization list (random permutated blocks with block size 2). Participating general practitioners in each primary care clinic examined the study patients themselves. 20 clinics were finally randomized to either the IG or CG. Participating general practitioners were encouraged to continuously recruit all eligible study patients from September 2007 to the end of December 2010. Each general practitioner was asked to recruit no fewer than 10 patients, if possible, but no more than 13 who satisfied the criteria for eligibility to participate in the study. Our study protocol called for 10 patients 
per clinic; however in practice we permitted a range of 7-13 patients per clinic. The higher number was allowed to maintain statistical power in the event of dropouts and the lower number was permitted in clinics where in 10 patients could not be enrolled.

Study participants were men and women from 20 to 79 years of age with type 2 diabetes and $\mathrm{HbA}_{1 \mathrm{c}}$ concentrations of $6.5 \%$ (NGSP) or over and who were receiving treatment by the assigned general practitioner in the primary care clinic. The value for $\mathrm{HbA}_{1 \mathrm{c}}$ (\%) was estimated as a National Glycohemoglobin Standardization Program (NGSP) equivalent value (\%) calculated by the formula $\mathrm{HbA}_{1 \mathrm{c}}(\%)=\mathrm{HbA}_{1 \mathrm{c}}$ Japan Diabetes Society (JDS) (\%) $+0.4 \%$, considering the relational expression of $\mathrm{HbA}_{1 \mathrm{c}}$ (JDS) (\%) measured by the previous Japanese standard substance and measurement methods and $\mathrm{HbA}_{1 \mathrm{c}}$ (NGSP) [12]. Therefore, 6.5\% (NGSP in the protocol paper [11]) is equivalent to $6.1 \%$ (JDS in this paper).

\section{Intervention and control groups}

The IG received structured individual-based lifestyle education that mainly encouraged the reduction in energy intake at dinner and an increase in vegetable intake at breakfast and lunch. Support for self-management of glycemic control, such as by diet, exercise, and stress management, was provided in 3 or 4 sessions with trained registered dietitians during the study period. The program for the IG was structured in four steps: "Basic information on glycemic control", "Actions for glycemic control", "Daily activities for glycemic control", and "Management of stress for glycemic control". We developed this program based on some of the strategies described in previous studies [13-15]. An assessment sheet, which was developed by consulting evidence-based practice guidelines for treatment of diabetes in Japan [15], was used. Patients decided on one or two short-term goals for glycemic control to be achieved in the next month based on the results of the FFQW82 and advice by registered dietitians. Sedentary participants were encouraged to increase basal physical activity. We recommended a gradual increase in physical activity in daily life rather than a formal fitness regimen or sports activity during leisure time. Before the start of the study, registered dietitians had the opportunity to gain experience with the intervention protocol under supervision by the project team.

Patients in the CG received information on dietary intake estimated using the FFQW82 and general advice on glycemic control by registered dietitians. A consultation by a dietitian was provided once with a month of randomization. The general advice was that which was usually given for glycemic control usually given by a general practitioner or a nurse in a clinic, such as "don't eat too much eat at dinner", "eat more vegetables", "do exercise", and so on. As for clinics without dietitians
(11 clinics; 6 for IG, 5 for CG), registered dietitians were randomly allocated. Four registered dietitians visited more than one of these clinics. Training of registered dietitians was conducted based on an instruction manual and thus did not differ between those at the intervention clinics and control clinics.

\section{Study hypothesis}

The hypothesis underlying the study is that participation in the IG would decrease the $\mathrm{HbA}_{1 \mathrm{c}}$ level by $15 \%$ from baseline (primary endpoint) after 6 months whereas we assumed that such a decrease would not occur in the CG. The value of a $15 \%$ decrease in the $\mathrm{HbA}_{1 \mathrm{c}}$ level was decided through reference to materials published in the USA [13] and through our experience with a previous survey [16].

\section{Outcome measures}

The primary endpoint was a change from the baseline $\mathrm{HbA}_{1 \mathrm{c}}$ level after 6 months of education. Secondary endpoints were changes at 6 months from baseline in other clinical data such as body mass index (BMI), blood pressure, fasting plasma glucose (FPG), and the lipid profiles (low density lipoprotein [LDL], high density lipoprotein [HDL], triglycerides [TG]). Dietary intakes were assessed using the FFQW82. Energy and vegetable intakes (whole day and each meal) and dietry fiber intake (whole day), proportions of carbohydrate, protein, and fat to total energy intakes were examined as secondary endpoints.

Measurements were made at baseline, at 3 months, and at 6 months (endpoint). However, because the changes in the endpoints between the IG and CG were the effect sizes in the present study, we used the measures at 3 months only for the last observation carried forward (LOCF) analysis.

All clinical data were obtained by general practitioners in the course of their usual clinical practice and by their generally used methods. We then extracted these data from their medical records. Our protocol stated that waist circumference would be a secondary outcome measure, but waist circumference measurements were missing for some patients, and there appeared to be large variations in the measurements for some individuals. Thus we eliminated waist circumference from the analysis. We assessed physical activity levels at baseline and at 6 months using the question "How frequently do you engage in physical activity or aerobic exercise such as walking, swimming, physical training, etc. for 10 minutes or more in a week?" The response was classified into 3 levels: "none", "1-3 day(s) per week", and " 4 days or more per week". Because the SILE program concentrated on dietary modifications, we used the levels of physical activity at baseline as an adjusted variable in the multivariate adjusted model 
(Model 4). Changes in levels of physical activity could affect outcomes. We added such changes in the multivariate adjusted model (Model 4).

\section{Statistical analysis}

Pearson correlation coefficients for changes in outcome measures were obtained.

Intention-to-treat (ITT) analysis was conducted. The LOCF method and a multiple imputation (MI) method using chained equations under the assumption of missing at random (MAR) [17] were used for handling missing data. Per-protocol analysis (PPA) with the complete data set (CDS) was conducted as a sensitivity analysis. Mixedeffects linear models were used to examine the effects of the treatment and cluster effect. Namely, in order to assess within-clinic $\left(S_{\mathrm{w}}^{2}\right)$ and between-clinic $\left(\mathrm{S}_{\mathrm{b}}^{2}\right)$ variances, mixedeffects linear models were used, which included a crude model (Model 1), a baseline-adjusted model (Model 2), baseline, gender, age, and BMI-adjusted model (Model 3), and multivariate-adjusted (gender, age, BMI, smoking habit, baseline and change in physical activity level, family history of type 2 diabetes, and complications) model (Model 4) using individual data.

A significance level of 5\% (two sided) was used for all tests. All statistical analyses were performed using SAS version 9.2 for Windows (SAS Institute, Inc., Cary, NC, USA).

\section{Results}

Following the guidelines of CONSORT [18], Figure 1 shows a flow diagram of progress of the clusters and individuals through phases of the randomized trial. In total, 20 clinics were randomized to either the IG (10 clinics) or CG (10 clinics), and 215 patients (113 IG, 102 CG) were recruited. Eleven patients (5 IG, 6 CG) did not meet the inclusion criteria and 11 patients (8 IG, 3 CG) could not complete the FFQW82. Finally, 193 patients were deemed eligible and assigned to their respective groups (100 IG; 93 CG) according to the allocation of the clinic where they received treatment. Therefore 193 patients were used for ITT analysis. During the study, 39 patients discontinued participation because they had left the area, changed clinics, became hospitalized, increased dosage or changed hypoglycemic agents, started or changed dosage of insulin, refused to continue, or could no longer be contacted (see Figure 1). Thus, PPA included 154 patients (84 [80\%] IG, 70 [75\%] CG). The background characteristics of participants in the IG and CG are shown in Table 1. Overall mean age was 61.3 years (60.4 years IG, 62.3 years CG). Table 2 shows baseline and 6-month follow-up statistics on the outcome measures in both study groups.

The 6-month ITT/LOCF analysis showed a significantly greater mean change in $\mathrm{HbA}_{1 \mathrm{c}}$ from baseline $(95 \%$ confidence interval) in the IG compared with the CG: $-0.7 \%$ vs. $-0.2 \%$; difference $-0.5 \%(-0.8 \%$ to $-0.2 \%), \mathrm{p}=0.004$ (Model 1). Those values for the baseline adjusted analysis

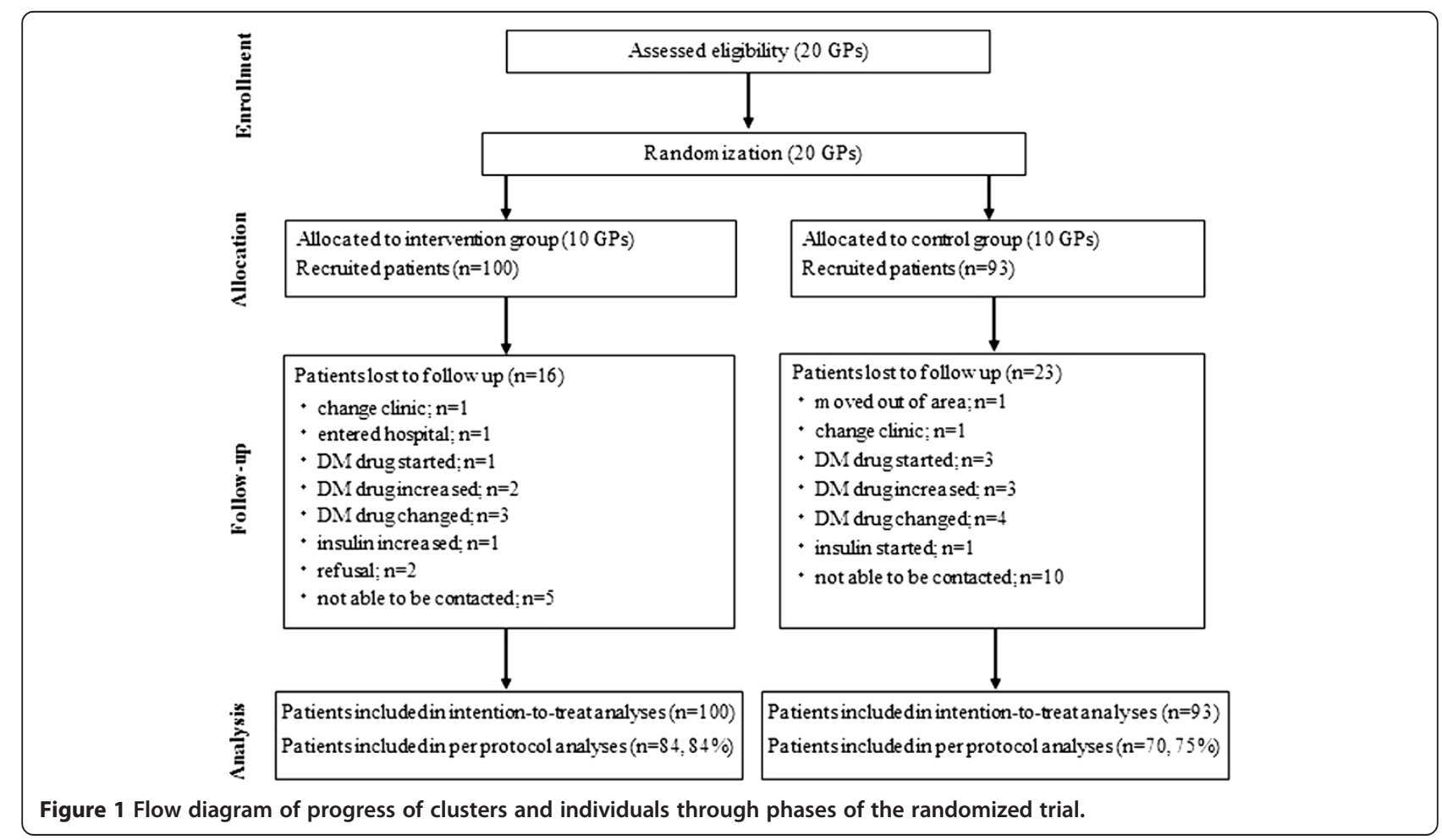


Table 1 Background characteristics of patients with type 2 diabetes allocated to intervention group or control group

\begin{tabular}{|c|c|c|}
\hline & Intervention group $(n=100)$ & Control group $(n=93)$ \\
\hline Age (yr) & $60.4(11.4)$ & $62.3(10.1)$ \\
\hline Women & $55(55 \%)$ & $54(58 \%)$ \\
\hline \multicolumn{3}{|l|}{ Smoking status } \\
\hline Not smoking & $88(88 \%)$ & $78(84 \%)$ \\
\hline Current smoking & $12(12 \%)$ & $13(14 \%)$ \\
\hline Past smoking & $0(0 \%)$ & $2(2 \%)$ \\
\hline \multicolumn{3}{|l|}{ Family history of type 2 diabetes } \\
\hline Having & $49(49 \%)$ & $34(37 \%)$ \\
\hline Not having & $46(46 \%)$ & $48(52 \%)$ \\
\hline Unknown & $5(5 \%)$ & $11(12 \%)$ \\
\hline \multicolumn{3}{|l|}{ Complications $\$$} \\
\hline None & $14(14 \%)$ & $12(12 \%)$ \\
\hline Hypertension & $59(59 \%)$ & $56(60 \%)$ \\
\hline Dyslipidemia & $21(21 \%)$ & $22(24 \%)$ \\
\hline \multicolumn{3}{|l|}{ Diabetes treatment } \\
\hline Diet only & $36(36 \%)$ & $31(33 \%)$ \\
\hline Oral hypoglycemic only & $54(54 \%)$ & $50(54 \%)$ \\
\hline Insulin and oral hypoglycemic & $5(5 \%)$ & $5(5 \%)$ \\
\hline Insulin only & $5(5 \%)$ & $7(8 \%)$ \\
\hline \multicolumn{3}{|l|}{ Other Medication $\$$} \\
\hline None & $25(25 \%)$ & $39(42 \%)$ \\
\hline Antihypertensive & $60(60 \%)$ & $39(42 \%)$ \\
\hline Lipid modifying & $46(46 \%)$ & $33(35 \%)$ \\
\hline
\end{tabular}

Data are mean (SD) or number (\%).

\$ multiple responses.

were $-0.6 \%$ vs. $-0.2 \%$; difference $-0.5 \%$ ( $-0.8 \%$ to $-0.2 \%$ ), $\mathrm{p}=0.004$ (Model 2). Significant improvements were also shown for gender, age, and BMI adjusted analysis (Model 3) $(\mathrm{p}=0.003)$ and for multivariate-adjusted analysis (Model 4) $(\mathrm{p}=0.011)$. Further analyses of the $\mathrm{HbA}_{1 \mathrm{c}}$ level with PPA/CDS and MI method showed similar significant effects. A tendency toward improvement was observed but the improvement was not statistically significant for the other clinical outcome measures, such as BMI, FPG, systolic blood pressure, diastolic blood pressure, LDL, HDL, and TG (Table 3.) Because FPG, HDL, and TG included many missing data and showed a large variance, the MI solutions were not converged and the estimates by the MI method for those were not obtained.

Larger energy intake at dinner $(r=0.29, \mathrm{p}=0.001)$ and larger fat intake at dinner $(\mathrm{r}=0.17, \mathrm{p}=0.055)$ were correlated with an increase in the $\mathrm{HbA}_{1 \mathrm{c}}$ level whereas larger vegetable intake at breakfast $(\mathrm{r}=-0.21, \mathrm{p}=0.015)$ and for the whole day $(\mathrm{r}=-0.18, \mathrm{p}=0.042)$ were correlated with reductions in the $\mathrm{HbA}_{1 \mathrm{c}}$ level. Increases in $\mathrm{BMI}(\mathrm{r}=0.28$, $\mathrm{p}<0.001)$, FPG (0.47, $\mathrm{p}<0.001)$, LDL $(\mathrm{r}=0.22, \mathrm{p}=0.011)$, and TG $(r=0.34, p<0.001)$ were correlated with increases in $\mathrm{HbA}_{1 \mathrm{c}}$. This suggests that the changes between endpoints were moderately correlated with each other.

Results of the analyses for dietary outcomes are summarized in Table 4. There was a statistically significant difference at 6 months from baseline in energy intake at dinner in the IG compared with the CG when all models were used for both the ITT/LOCF and PPA/CDS analyses, but not MI method (Table 4). There was a statistically significant mean change at 6 months from baseline between groups in vegetable intake for a whole day, breakfast, and lunch $(\mathrm{p}=0.000 \sim 0.043$ for Model 1 to Model 3) (Figure 2). Specifically, intake of vegetables in the IG was significantly greater than in the CG for a whole day breakfast and lunch. For dietary fiber intake, a statistically significant increase was shown only for Model 1 and Model 2 by ITT/LOCF. No statistically significant changes were shown for the other nutrient outcomes such as proportions of carbohydrate, protein, and total fat of total energy.

\section{Discussion}

This 6-month cluster randomized controlled trial to assess the effectiveness of a structured individualized 
Table 2 Baseline and at 6th months clinical and dietary characteristics

\begin{tabular}{|c|c|c|c|c|c|c|c|c|c|c|c|c|}
\hline \multirow[b]{3}{*}{ Characteristics } & \multicolumn{6}{|c|}{ Intervention group $(n=100)$} & \multicolumn{6}{|c|}{ Control group $(n=93)$} \\
\hline & \multicolumn{3}{|c|}{ Baseline } & \multicolumn{3}{|c|}{ at 6 th months } & \multicolumn{3}{|c|}{ Baseline } & \multicolumn{3}{|c|}{ at 6 th months } \\
\hline & $\mathrm{n}$ & Mean & $\mathrm{SD}^{*}$ & $\mathrm{n}$ & Mean & $\mathrm{SD}^{*}$ & n & Mean & $S D^{*}$ & $\mathrm{n}$ & Mean & $\mathrm{SD}^{*}$ \\
\hline $\mathrm{HbA}_{1 c}(\%)^{\#}$ & 100 & 7.6 & 1.4 & 84 & 6.7 & 1.2 & 93 & 7.3 & 1.1 & 70 & 7.0 & 1.0 \\
\hline BMI $\left(\mathrm{kg} / \mathrm{m}^{2}\right)$ & 100 & 26.3 & 4.6 & 91 & 25.6 & 4.3 & 93 & 24.9 & 4.6 & 82 & 24.5 & 4.4 \\
\hline Fasting plasma glucose (mg/dl) & 79 & 174 & 70 & 78 & 145 & 63 & 77 & 160 & 71 & 66 & 134 & 48 \\
\hline Systolic blood pressure (mmHg) & 100 & 133 & 17 & 85 & 132 & 15 & 93 & 132 & 17 & 81 & 130 & 16 \\
\hline Diastolic blood pressure (mmHg) & 100 & 78 & 12 & 84 & 77 & 11 & 93 & 75 & 12 & 81 & 72 & 11 \\
\hline LDL cholesterol (mg/dl) & 96 & 127 & 29 & 87 & 121 & 29 & 89 & 122 & 30 & 71 & 122 & 28 \\
\hline HDL cholesterol I (mg/dl) & 87 & 56 & 16 & 80 & 58 & 20 & 88 & 56 & 13 & 68 & 59 & 15 \\
\hline Triglycerides (mg/dl) & 84 & 151 & 84 & 78 & 135 & 104 & 77 & 141 & 74 & 69 & 133 & 70 \\
\hline \multicolumn{13}{|l|}{ Energy intakes } \\
\hline Whole day (kcal) & 100 & 1686 & 272 & 80 & 1624 & 220 & 93 & 1671 & 238 & 68 & 1655 & 259 \\
\hline Breakfast (kcal) & 100 & 412 & 161 & 80 & 423 & 137 & 93 & 403 & 151 & 68 & 401 & 149 \\
\hline Lunch (kcal) & 100 & 551 & 159 & 80 & 535 & 130 & 93 & 551 & 125 & 68 & 540 & 143 \\
\hline Dinner (kcal) & 100 & 741 & 100 & 80 & 700 & 91 & 93 & 732 & 95 & 68 & 726 & 99 \\
\hline Proportion of carbohydrate (\%) & 100 & 55.3 & 2.5 & 80 & 55.2 & 2.4 & 93 & 55.1 & 2.9 & 68 & 54.6 & 4.2 \\
\hline Proportion of protein (\%) & 100 & 15.9 & 1.3 & 80 & 16.1 & 0.8 & 93 & 16.0 & 1.0 & 68 & 16.3 & 1.5 \\
\hline Proportion of fat (\%) & 100 & 28.8 & 2.0 & 80 & 28.7 & 2.0 & 93 & 28.9 & 2.3 & 68 & 29.2 & 3.1 \\
\hline Fiber intake (g) & 100 & 12.1 & 2.3 & 80 & 12.8 & 2.1 & 93 & 12.6 & 2.1 & 68 & 12.7 & 2.5 \\
\hline \multicolumn{13}{|l|}{ Vegetable intakes } \\
\hline Whole day (g) & 100 & 196.5 & {$[155,242]$} & 80 & 236.5 & {$[202.0,281.5]$} & 93 & 223.0 & {$[183,275]$} & 68 & 208.5 & {$[175,263.5]$} \\
\hline Breakfast (g) & 100 & 26.5 & {$[8.0,45.5]$} & 80 & 42.0 & {$[30.0,65.5]$} & 93 & 38.0 & {$[13,60]$} & 68 & 40.0 & {$[15.5,52.5]$} \\
\hline Lunch (g) & 100 & 38.5 & {$[20.5,60]$} & 80 & 58.0 & {$[37.5,78]$} & 93 & 55.0 & {$[28,75]$} & 68 & 44.0 & {$[23,69.5]$} \\
\hline Dinner $(\mathrm{g})$ & 100 & 130.0 & {$[118,143.5]$} & 80 & 137.0 & {$[124.5,148.5]$} & 93 & 132.0 & {$[120,147]$} & 68 & 134.0 & {$[121,147]$} \\
\hline Exercise status & 100 & & & 82 & & & 93 & & & 64 & & \\
\hline None & & 54 & $54 \%$ & & 24 & $29 \%$ & & 35 & $38 \%$ & & 27 & $42 \%$ \\
\hline 1-3 day(s)/ wk & & 19 & $19 \%$ & & 14 & $17 \%$ & & 16 & $17 \%$ & & 7 & $11 \%$ \\
\hline 4 days or over/ wk & & 27 & $27 \%$ & & 44 & $54 \%$ & & 42 & $45 \%$ & & 30 & $47 \%$ \\
\hline Exercise status: change from baseline & 82 & & & & & & 62 & & & & & \\
\hline Less & & & & & 9 & $11 \%$ & & & & & 13 & $20 \%$ \\
\hline Not change & & & & & 43 & $52 \%$ & & & & & 40 & $63 \%$ \\
\hline More & & & & & 30 & $37 \%$ & & & & & 11 & $17 \%$ \\
\hline
\end{tabular}

Dada are mean (SD), Median [25\%tile, 75\%tile], or number (\%),

* SD: standard deviation.

\# Value of $\mathrm{HbA}_{1 \mathrm{C}}$ is $\mathrm{JDS}^{15}$

lifestyle education program aimed at modifying dietary intake by meal for type 2 diabetes patients in primary care clinics successfully registered 193 participants. The ITT/LOCF analysis to compare the mean changes at 6 months from baseline in the $\mathrm{HbA}_{1 \mathrm{c}}$ level showed a significantly greater reduction in the IG compared to the CG $(-0.5 \%, \mathrm{p}=0.004)$. The sensitivity analyses by baseline adjusted analyses of PPA/CDS and ITT/MI showed similarly significant effectiveness. In the analyses of dietary intake, compared with the CG, in the IG energy intake at dinner decreased significantly from baseline and vegetable intake significantly increased for the whole day, breakfast, and lunch in the all models. These results were confirmed by several sensitivity analyses, whereas statistical significance was not shown for the other clinical and dietary outcome measures. These results suggested that the structured individual-based lifestyle education by registered dietitians for glycemic control in primary care settings has the potential to improve $\mathrm{HbA}_{1 \mathrm{c}}$ levels in patients with type 2 diabetes.

To encourage reduction in energy intake at dinner and increase in vegetable intake at breakfast and lunch is useful in lowering the $\mathrm{HbA}_{1 \mathrm{c}}$ level to improve glycemic control with type 2 diabetes patients not only in Japan but also in other countries. Furthermore, although not significant, the proportion of patients achieving the 
Table 3 Mean change at 6 th months from baseline in clinical data

\begin{tabular}{|c|c|c|c|c|c|c|c|c|c|c|c|c|c|c|c|c|c|c|}
\hline & \multicolumn{3}{|c|}{ Intervention } & \multicolumn{3}{|c|}{ Control } & \multicolumn{3}{|c|}{ Model 1 (crude) } & \multicolumn{3}{|c|}{ Model 2 (adjusted) } & \multicolumn{3}{|c|}{ Model 3 (adjusted) } & \multicolumn{3}{|c|}{ Model 4 (adjusted) } \\
\hline & Mean & \pm & SE & Mean & \pm & SE & Difference & $95 \% \mathrm{Cl}$ & $p$-value & Difference & $95 \% \mathrm{Cl}$ & $p$-value & Differences & $95 \% \mathrm{Cl}$ & $p$-value & Difference & $95 \% \mathrm{Cl}$ & $p$-value \\
\hline \multicolumn{19}{|c|}{$\mathrm{HbA}_{1 \mathrm{c}}(\%)^{\#}$} \\
\hline $\mathrm{LOCF}^{1)}$ & -0.7 & \pm & 0.1 & -0.2 & \pm & 0.1 & -0.5 & $(-0.8$ to -0.2$)$ & 0.004 & -0.5 & $(-0.8$ to -0.2$)$ & 0.004 & -0.5 & $(-0.8$ to -0.2$)$ & 0.003 & -0.5 & $(-0.9$ to -0.1$)$ & 0.011 \\
\hline $\mathrm{CDS}^{2)}$ & -0.7 & \pm & 0.1 & -0.2 & \pm & 0.1 & -0.5 & $(-0.9$ to -0.1$)$ & 0.009 & -0.4 & $(-0.8$ to -0.1$)$ & 0.014 & -0.5 & (-0.1 to -0.8$)$ & 0.013 & -0.5 & $(-1.0$ to -0.1$)$ & 0.028 \\
\hline$\overline{M 1^{3)}}$ & -0.7 & \pm & 0.1 & -0.3 & \pm & 0.1 & -0.5 & $(-0.9$ to -0.1$)$ & 0.030 & -0.4 & $(-0.8$ to -0.1$)$ & 0.041 & -0.4 & $(-0.8$ to -0.2$)$ & 0.045 & -0.4 & $(-0.6$ to -0.0$)$ & 0.045 \\
\hline \multicolumn{19}{|c|}{$\mathrm{BMI}\left(\mathrm{kg} / \mathrm{m}^{2}\right)$} \\
\hline $\mathrm{LOCF}^{1)}$ & -0.5 & \pm & 0.1 & -0.3 & \pm & 0.2 & -0.2 & $(-0.7$ to 0.2$)$ & 0.351 & -0.1 & $(-0.6$ to 0.4$)$ & 0.598 & -0.1 & (-0.6 to 0.3$)$ & 0.548 & -0.3 & $(-0.8$ to 0.2$)$ & 0.221 \\
\hline $\operatorname{CDS}^{2)}$ & -0.6 & \pm & 0.2 & -0.3 & \pm & 0.2 & -0.3 & (-0.8 to 0.1$)$ & 0.146 & -0.2 & ( -0.8 to 0.3$)$ & 0.331 & -0.3 & ( -0.8 to 0.3$)$ & 0.297 & -0.3 & ( -0.9 to 0.2$)$ & 0.216 \\
\hline$\overline{M 1^{3)}}$ & -0.5 & \pm & 0.1 & -0.3 & \pm & 0.2 & -0.2 & $(-0.7$ to 0.2$)$ & 0.351 & -0.1 & $(-0.7$ to 0.5$)$ & 0.693 & -0.1 & $(-0.7$ to 0.4$)$ & 0.633 & -0.1 & $(-0.6$ to 0.5$)$ & 0.829 \\
\hline \multicolumn{19}{|c|}{$\mathrm{FPG}(\mathrm{mg} / \mathrm{dl})$} \\
\hline LOCF $^{1)}$ & -19 & \pm & 8 & -20 & \pm & 8 & 1 & $(-23$ to 25$)$ & 0.919 & 8 & (-11 to 28$)$ & 0.367 & 9 & (-11 to 29$)$ & 0.347 & 22 & $(-10$ to 54$)$ & 0.165 \\
\hline $\operatorname{CDS}^{2)}$ & -20 & \pm 10 & 10 & -14 & \pm & 11 & 7 & (-37 to 23$)$ & 0.633 & 1 & ( -23 to 25$)$ & 0.933 & 0 & (-25 to 25$)$ & 0.993 & 5 & (-33 to 43$)$ & 0.792 \\
\hline \multicolumn{19}{|l|}{$\overline{M 1^{3)} \$}$} \\
\hline \multicolumn{19}{|c|}{$\mathrm{SBP}(\mathrm{mmHg})$} \\
\hline $\mathrm{LOCF}^{1)}$ & -1 & \pm & 3 & 0 & \pm & 3 & 1 & $(-9$ to 7$)$ & 0.748 & -1 & $(-7$ to 6$)$ & 0.802 & 0 & ( -7 to 6$)$ & 0.963 & 0 & ( -8 to 8$)$ & 0.951 \\
\hline $\operatorname{CDS}^{2)}$ & -1 & \pm & 3 & -2 & \pm & 3 & 1 & ( -7 to 9 ) & 0.804 & 2 & ( -5 to 9$)$ & 0.514 & 4 & ( -4 to 9 ) & 0.416 & 4 & $(-5$ to 12$)$ & 0.370 \\
\hline$\overline{M 1^{3)}}$ & -1 & \pm & 3 & -2 & \pm & 3 & -1 & (-9 to 7 ) & 0.738 & -2 & (-8 to 5 ) & 0.593 & -2 & (-9 to 5 ) & 0.523 & -3 & (-11 to 4$)$ & 0.368 \\
\hline \multicolumn{19}{|c|}{$\mathrm{DBP}(\mathrm{mmHg})$} \\
\hline LOCF $^{1)}$ & -1 & \pm & 1 & -3 & \pm & 2 & 1 & $(-3$ to 6$)$ & 0.560 & -3 & $(-1$ to 7$)$ & 0.164 & -2 & $(-2$ to 6$)$ & 0.239 & 4 & $(-1$ to 8$)$ & 0.088 \\
\hline $\mathrm{CDS}^{2)}$ & -0 & \pm & 1 & -4 & \pm & 1 & 3 & (-1 to 7$)$ & 0.159 & 4 & (-0 to 8$)$ & 0.050 & 4 & (-0 to 8$)$ & 0.073 & 5 & (0 to 10$)$ & 0.049 \\
\hline$\overline{M 1^{3)}}$ & -1 & \pm & 1 & -3 & \pm & 2 & -2 & (-7 to 2$)$ & 0.296 & -3 & ( -8 to 1$)$ & 0.120 & -3 & ( -8 to 1$)$ & 0.166 & -3 & (-8 to 2$)$ & 0.171 \\
\hline \multicolumn{19}{|c|}{ LDL(mg/dl) } \\
\hline $\mathrm{LOCF}^{1)}$ & -5 & \pm & 2 & -1 & \pm & 2 & -4 & $(-10$ to 3$)$ & 0.286 & -2 & ( -8 to 3$)$ & 0.387 & -3 & $(-10$ to 3$)$ & 0.245 & -4 & $(-13$ to 5$)$ & 0.344 \\
\hline $\mathrm{CDS}^{2)}$ & -4 & \pm & 2 & 0 & \pm & 3 & -4 & $(-12$ to 3$)$ & 0.241 & -3 & $(-10$ to 4$)$ & 0.371 & -4 & $(-11$ to 3$)$ & 0.252 & -5 & $(-16$ to 5$)$ & 0.283 \\
\hline$\overline{M 1^{3)}}$ & -5 & \pm & 4 & 2 & \pm & 4 & 7 & ( 2 to 12 ) & 0.198 & 6 & ( 0 to 10 ) & 0.250 & 7 & $(-4$ to 17$)$ & 0.196 & 7 & (-6 to 18$)$ & 0.223 \\
\hline \multicolumn{19}{|c|}{$\mathrm{HDL}(\mathrm{mg} / \mathrm{dl})$} \\
\hline $\mathrm{LOCF}^{1)}$ & -1 & \pm & 1 & 1 & \pm & 1 & -0 & $(-4$ to 3$)$ & 0.823 & -0 & $(-4$ to 3$)$ & 0.863 & 0 & $(-3$ to 4$)$ & 0.861 & 2 & $(-3$ to 8$)$ & 0.393 \\
\hline $\mathrm{CDS}^{2)}$ & 1 & \pm & 2 & 2 & \pm & 2 & -1 & ( -6 to 4$)$ & 0.745 & -1 & ( -6 to 4$)$ & 0.701 & 0 & ( -5 to 5$)$ & 0.994 & 2 & ( -3 to 8$)$ & 0.393 \\
\hline
\end{tabular}


Table 3 Mean change at 6th months from baseline in clinical data (Continued)

Triglycerides

$(\mathrm{mg} / \mathrm{d})$

\begin{tabular}{|c|c|c|c|c|c|c|c|c|c|c|c|c|c|c|c|c|c|c|}
\hline LOCF $^{1)}$ & -3 & \pm & 8 & -5 & \pm & 9 & 2 & $(-23$ to 26$)$ & 0.894 & 4 & (-20 to 28$)$ & 0.748 & 2 & ( -22 to 27$)$ & 0.239 & 7 & ( -28 to 43$)$ & 0.667 \\
\hline $\mathrm{CDS}^{2)}$ & -7 & \pm & 8 & -5 & \pm & 9 & -3 & (-29 to 24$)$ & 0.833 & 4 & $(-27$ to 25$)$ & 0.951 & -5 & (-31 to 22$)$ & 0.708 & -1 & ( -38 to 36$)$ & 0.953 \\
\hline
\end{tabular}

(CDSt)

SE: standard error, $95 \% \mathrm{Cl}$ : 95\% confidence interval, degree of freedom $=18$

\#Value of $\mathrm{HbA}_{1 C}$ is JDS ${ }^{15}$.

1) LOCF: last observation carried forward (IG: $n=100, C G: n=93$ ).

2) CDS: complete data set. (IG: $n=84), C G: n=70)$.

3) MI: Multiple imputation with all analysed variables (number of imputations $=200$ ) (IG: $n=100, C G: n=93$ ).

Model 1: crude.

Model 2: mixed model adjusted for baseline.

Model 3: mixed model adjusted for baseline, gender, age and BMI.

Model 4: mixed model adjusted for baseline, gender, age, BMl, smoking status, exercise status, change of exercise level, family history of type 2 diabetes, and complication.

${ }^{\$}$ The Ml models did not converge. 
Table 4 Mean change at 6 th months from baseline in dietary data

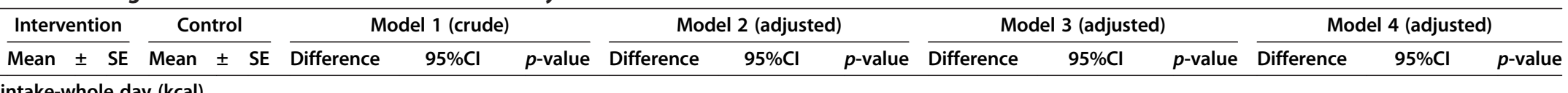

$\frac{\text { Mean } \pm \text { SE Mean }}{\text { Energy intake-whole day (kcal) }}$

\begin{tabular}{|c|c|c|c|c|c|c|c|c|c|c|c|c|c|c|c|c|c|c|}
\hline LOCF $^{1)}$ & -29 & \pm & 16 & -7 & \pm & 17 & -22 & (-23 to 67$)$ & 0.364 & -21 & $(-19$ to 61$)$ & 0.333 & -23 & $(-18$ to 64$)$ & 0.283 & -27 & $(-112$ to 9$)$ & 0.222 \\
\hline$\overline{\mathrm{CDS}^{2)}}$ & -54 & \pm & 22 & 9 & \pm & 24 & -54 & $(-10$ to 117$)$ & 0.114 & -50 & (- 1 to 108$)$ & 0.085 & -54 & (- 1 to 108$)$ & 0.073 & -53 & $(-151$ to -12$)$ & 0.034 \\
\hline$\left.M\right|^{3)}$ & -54 & + & 35 & -20 & + & 38 & -34 & $(-76$ to 145$)$ & 0519 & -33 & $(-68$ to 134$)$ & 0.493 & -39 & $(-62$ to 140$)$ & 0.420 & -52 & (-159 to 50$)$ & 0.321 \\
\hline
\end{tabular}

Energy intake-breakfast (kcal)

\begin{tabular}{|c|c|c|c|c|c|c|c|c|c|c|c|c|c|c|c|c|c|c|}
\hline LOCF $^{1)}$ & 19 & \pm & 11 & 10 & \pm & 12 & 8 & (-41 to 24$)$ & 0.619 & 11 & $(-41$ to 19$)$ & 0.480 & 11 & $(-41$ to 20$)$ & 0.505 & 12 & $(-56$ to 32$)$ & 0.598 \\
\hline $\mathrm{CDS}^{2)}$ & 17 & \pm & 15 & 23 & \pm & 17 & 6 & $(-39$ to 51$)$ & 0.793 & 2 & ( -43 to 38$)$ & 0.909 & 0 & (-42 to 41$)$ & 0.986 & 2 & (-50 to 55$)$ & 0.922 \\
\hline $\mathrm{Ml}^{3)}$ & 1 & \pm & 22 & 5 & \pm & 24 & -5 & (-59 to 68$)$ & 0.891 & 0 & (-65 to 64$)$ & 0.988 & -3 & (-61 to 66$)$ & 0.937 & 2 & $(-72$ to 62$)$ & 0.888 \\
\hline \multicolumn{19}{|c|}{ Energy intake-lunch (kcal) } \\
\hline $\mathrm{LOCF}^{1)}$ & -6 & \pm & 10 & -6 & \pm & 10 & 0 & (-28 to 29$)$ & 0.974 & -1 & (-26 to 27$)$ & 0.965 & -3 & $(-24$ to 30$)$ & 0.829 & 22 & (-17 to 62$)$ & 0.567 \\
\hline $\mathrm{CDS}^{2)}$ & -13 & \pm & 13 & -2 & \pm & 14 & -11 & ( -27 to 49$)$ & 0.570 & -11 & (-27 to 49$)$ & 0.551 & -13 & (-23 to 49$)$ & 0.488 & -34 & ( -13 to 82$)$ & 0.178 \\
\hline$\overline{M 1^{3)}}$ & -16 & \pm & 21 & -12 & \pm & 22 & -3 & (-56 to 64$)$ & 0.899 & -6 & (-48 to 58$)$ & 0.808 & -11 & $(-41$ to 63$)$ & 0.694 & -24 & $(-34$ to 80$)$ & 0.441 \\
\hline
\end{tabular}

\section{Energy intake-dinner (kcal)}

\begin{tabular}{|c|c|c|c|c|c|c|c|c|c|c|c|c|c|c|c|c|c|c|}
\hline LOCF $^{1)}$ & -23 & \pm & 6 & -4 & \pm & 6 & -19 & $(-35$ to -3$)$ & 0.031 & -19 & $(-35$ to -2$)$ & 0.040 & -19 & $(-35$ to -3$)$ & 0.030 & -29 & $(-48$ to -10$)$ & 0.007 \\
\hline $\mathrm{CDS}^{2)}$ & -29 & \pm & 7 & 2 & \pm & 8 & -31 & $(-51$ to -11$)$ & 0.008 & -31 & $(-51$ to -11$)$ & 0.007 & -37 & $(-58$ to -16$)$ & 0.003 & -41 & $(-61$ to -20$)$ & 0.001 \\
\hline$\overline{\mathrm{Ml}^{3)}}$ & -30 & \pm & 10 & -7 & \pm & 11 & -23 & (-51 to 5$)$ & 0.136 & -22 & (-50 to 6$)$ & 0.147 & -24 & (-50 to 3$)$ & 0.110 & -24 & (-54 to 4$)$ & 0.114 \\
\hline
\end{tabular}

Proportion of carbohydrate to total energy intake (\%)

\begin{tabular}{|c|c|c|c|c|c|c|c|c|c|c|c|c|c|c|c|c|c|c|}
\hline $\mathrm{LOCF}^{1)}$ & 0.0 & \pm & 0.3 & 0.6 & \pm & 0.4 & 0.6 & ( -0.4 to 1.6$)$ & 0.246 & 0.7 & ( -0.3 to 1.6$)$ & 0.193 & 0.6 & ( -0.3 to 1.5$)$ & 0.205 & 0.2 & ( -1.0 to 1.3$)$ & 0.768 \\
\hline$\overline{\mathrm{CDS}^{2)}}$ & 0.0 & \pm & 0.4 & -0.5 & \pm & 0.4 & 0.4 & (-0.6 to 1.5$)$ & 0.373 & 0.4 & ( -0.5 to 1.3$)$ & 0.390 & 0.3 & ( -0.5 to 1.2$)$ & 0.438 & -0.3 & (-1.1 to 0.6$)$ & 0.559 \\
\hline $\mathrm{MI}^{3)}$ & -0.1 & + & 0.7 & 0.0 & + & 0.7 & 0.2 & $(-2.0$ to 20$)$ & 0.883 & 0.0 & (-2.0 to 2.1$)$ & 0.985 & -0.1 & $(-1.8$ to 20$)$ & 0.945 & -0.3 & $(-1.7$ to 2.3$)$ & 0,764 \\
\hline
\end{tabular}

Proportion of protein to total energy intake (\%)

\begin{tabular}{|c|c|c|c|c|c|c|c|c|c|c|c|c|c|c|c|c|c|c|}
\hline LOCF $^{1)}$ & 0.2 & \pm & 0.1 & 0.2 & \pm & 0.1 & 0.0 & $(-0.3$ to 0.3$)$ & 0.837 & 0.0 & $(-0.4$ to 0.3$)$ & 0.764 & 0.1 & $(-0.4$ to 0.2$)$ & 0.759 & 0.1 & $(-0.3$ to 0.5$)$ & 0.633 \\
\hline$\overline{\mathrm{CDS}^{2)}}$ & 0.3 & \pm & 0.1 & 0.3 & \pm & 0.1 & 0.0 & $(-0.4$ to 0.4$)$ & 0.999 & 0.0 & $(-0.4$ to 0.3$)$ & 0.862 & 0.0 & (-0.4 to 0.4$)$ & 0.884 & 0.2 & $(-0.1$ to 0.6$)$ & 0.257 \\
\hline$\overline{M 1^{3)}}$ & 0.3 & \pm & 0.2 & 0.1 & \pm & 0.2 & -0.2 & (-0.9 to 0.5$)$ & 0.512 & -0.2 & $(-0.8$ to 0.5$)$ & 0.546 & -0.2 & (-0.8 to 0.5$)$ & 0.597 & -0.3 & (-0.3 to 0.6$)$ & 0.825 \\
\hline \multicolumn{19}{|c|}{ Proportion of total fat to total energy intake (\%) } \\
\hline LOCF $^{1)}$ & -0.2 & \pm & 0.3 & 0.3 & \pm & 0.3 & -0.6 & $(-1.3$ to 0.1$)$ & 0.152 & -0.6 & $(-1.3$ to 0.1$)$ & 0.111 & -0.6 & $(-1.2$ to 0.1$)$ & 0.110 & -0.3 & $(-1.2$ to 0.5$)$ & 0.435 \\
\hline$\overline{\mathrm{CDS}^{2)}}$ & -0.2 & \pm & 0.3 & 0.2 & \pm & 0.3 & -0.5 & $(-1.3$ to 0.4$)$ & 0.282 & -0.4 & $(-1.1$ to 0.3$)$ & 0.287 & -0.3 & (-0.9 to 0.3$)$ & 0.307 & 0.1 & $(-0.6$ to -0.7$)$ & 0.861 \\
\hline$\overline{\mathrm{MI}^{3)}}$ & -0.2 & \pm & 0.6 & -0.2 & \pm & 0.6 & 0.0 & (-1.9 to 1.8$)$ & 0.755 & -0.1 & $(-1.5$ to 1.6$)$ & 0.941 & 0.0 & $(-1.4$ to 1.5$)$ & 0.953 & 0.1 & ( -1.6 to 1.4$)$ & 0.900 \\
\hline \multicolumn{19}{|c|}{ Vegetable intake-whole day (g) } \\
\hline LOCF $^{1)}$ & 35.1 & \pm & 5.5 & -0.2 & \pm & 5.7 & 35.3 & (19.6 to 50.6$)$ & 0.000 & 29.0 & (14.9 to 43.1$)$ & 0.001 & 28.6 & $(14.3$ to 42.9$)$ & 0.001 & 25.5 & (5.9 to 45.1$)$ & 0.021 \\
\hline $\operatorname{CDS}^{2)}$ & 43.2 & \pm & 6.3 & 5.4 & \pm & 7,1 & 37.8 & (19.2 to 56.4$)$ & 0.001 & 31.4 & (13.2 to 49.6$)$ & 0.003 & 30.1 & (11.6 to 48.7$)$ & 0.005 & 28.6 & (8.9 to 48.2 ) & 0.011 \\
\hline$\overline{\mathrm{MI}^{3)}}$ & 39.1 & \pm & 8.5 & -1.4 & \pm & 9.3 & 40.5 & (13.2 to 67.9$)$ & 0.007 & 31.6 & (8.5 to 56.7 ) & 0.021 & 31.6 & (7.8 to 55.6$)$ & 0.024 & 30.5 & (5.6 to 55.4 ) & 0.034 \\
\hline
\end{tabular}


Table 4 Mean change at 6th months from baseline in dietary data (Continued)

Vegetable intake-breakfast (g)

\begin{tabular}{|c|c|c|c|c|c|c|c|c|c|c|c|c|c|c|c|c|c|c|}
\hline LOCF $^{1)}$ & 16.0 & \pm & 2.8 & -0.3 & \pm & 2.8 & 16.3 & (8.6 to 23.9 ) & 0.001 & 13.0 & (5.9 to 20.0 ) & 0.002 & 12.7 & (6.5 to 18.9 ) & 0.001 & 14.3 & (4.6 to 23.7 ) & 0.001 \\
\hline $\operatorname{CDS}^{2)}$ & 20.2 & \pm & 3.0 & 0.8 & \pm & 3.3 & 19.4 & (10.5 to 28.3$)$ & 0.000 & 14.1 & (6.3 to 21.9 ) & 0.003 & 13.1 & (5.3 to 20.9 ) & 0.004 & 11.5 & (1.1 to 21.5$)$ & 0.043 \\
\hline$\overline{M 1^{3)}}$ & 15.5 & \pm & 4.2 & -0.5 & \pm & 4.5 & 16.0 & (3.9 to 28.3 ) & 0.021 & 13.0 & ( -0.3 to 22.5$)$ & 0.078 & 12.7 & $(-0.2$ to 21.3$)$ & 0.079 & 12.5 & ( -0.3 to 22.7$)$ & 0.062 \\
\hline \multicolumn{19}{|c|}{ Vegetable intake-lunch (g) } \\
\hline LOCF $^{1)}$ & 13.1 & \pm & 3.0 & 0.5 & \pm & 3.1 & 9.5 & (4.2 to 21.0 ) & 0.009 & 9.9 & (2.2 to 16.9 ) & 0.020 & 9.0 & (1.7 to 16.4 ) & 0.027 & 6.0 & (4.3 to 16.2 ) & 0.270 \\
\hline $\operatorname{CDS}^{2)}$ & 15.9 & \pm & 3.4 & 5.1 & \pm & 3.8 & 10.8 & (10.8 to 20.8) & 0.048 & 8.5 & (-0.4 to 17.5$)$ & 0.078 & 8.0 & $(-1.2$ to 17.2$)$ & 0.108 & 3.6 & (-8.0 to 15.1$)$ & 0.550 \\
\hline$\overline{\mathrm{M}^{3)}}$ & 15.0 & \pm & 4.5 & -0.3 & \pm & 4.9 & 15.3 & (0.6 to 30.0 ) & 0.042 & 10.9 & (-2.3 to 24.1$)$ & 0.113 & 10.5 & (-1.3 to 22.2$)$ & 0.106 & 9.8 & (-2.1 to 21.7$)$ & 0.134 \\
\hline
\end{tabular}

Vegetable intake-dinner (g)

\begin{tabular}{|c|c|c|c|c|c|c|c|c|c|c|c|c|c|c|c|c|c|c|}
\hline $\operatorname{LOCF}^{1)}$ & 6.4 & \pm & 2.8 & -0.6 & \pm & 2.9 & 7.2 & ( -0.8 to 14.8$)$ & 0.095 & 5.8 & $(-1.5$ to 13.1$)$ & 0.129 & 5.6 & $(-1.7$ to 12.9$)$ & 0.144 & 4.2 & (-4.8 to 13.3$)$ & 0.376 \\
\hline $\operatorname{cDS}^{2)}$ & 5.7 & \pm & 3.1 & 0.1 & \pm & 3.4 & 5.6 & $(-0.8$ to 16.9$)$ & 0.093 & 6.0 & $(-2.4$ to 14.9$)$ & 0.177 & 6.2 & $(-14.3$ to 45.1$)$ & 0.174 & 3.1 & $(-5.9$ to 45.1$)$ & 0.491 \\
\hline & 83 & + & 39 & -13 & + & 43 & 97 & $(-34$ to 198$)$ & 0132 & 82 & $(-34$ to 198$)$ & 0186 & 80 & $(-46$ to 207$)$ & 0196 & 82 & $(-38+0202)$ & 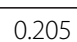 \\
\hline
\end{tabular}

\section{Dietary fiber intake (g)}

\begin{tabular}{|c|c|c|c|c|c|c|c|c|c|c|c|c|c|c|c|c|c|c|}
\hline LOCF $^{1)}$ & 0.7 & \pm & 0.2 & 0.1 & \pm & 0.2 & 0.6 & (0.1 to 1.0 ) & 0.022 & 0.5 & (0.1 to 0.9 ) & 0.039 & 0.5 & ( -0.1 to 1.0$)$ & 0.051 & 0.4 & (0.0 to 1.0 ) & 0.241 \\
\hline$\left(\operatorname{CDS}^{2)}\right.$ & 0.9 & \pm & 0.2 & 0.3 & \pm & 0.2 & 0.6 & (0.0 to 1.2 ) & 0.087 & 0.4 & $(-0.1$ to 1.0$)$ & 0.157 & 0.4 & $(-0.2$ to 1.0$)$ & 0.225 & 0.3 & $(-0.5$ to 1.0$)$ & 0.489 \\
\hline$\overline{\left.M\right|^{3)}}$ & 0.7 & \pm & 0.3 & 0.1 & \pm & 0.3 & 0.6 & $(-1.6$ to 0.4$)$ & 0.246 & 0.4 & $(-1.4$ to 0.5$)$ & 0.346 & 0.4 & $(-1.4$ to 0.6$)$ & 0.380 & 0.4 & $(-1.3$ to 0.6$)$ & 0.393 \\
\hline
\end{tabular}

SE: standard error, $95 \% \mathrm{Cl}$ : 95\% confidence interval, degree of freedom $=18$.

\# Value of $\mathrm{HbA}_{1 \mathrm{C}}$ is $\mathrm{JDS}^{15}$.

1) LOCF: last observation carried forward (IG: $n=100, C G: n=93$ ).

2) CDS: complete data set. (IG: $n=84, C G: n=70)$.

3) MI: Multiple imputation with all analyzed variables (number of imputations $=200$ ) (IG: $n=100, C G: n=93$ ).

Model 1: crude.

Model 2: mixed model adjusted for baseline.

Model 3: mixed model adjusted for baseline, gender, age and BML.

Model 4: mixed model adjusted for baseline, gender, age, BMI, smoking status, exercise status, change of exercise level, family history of type 2 diabetes, and complication. 


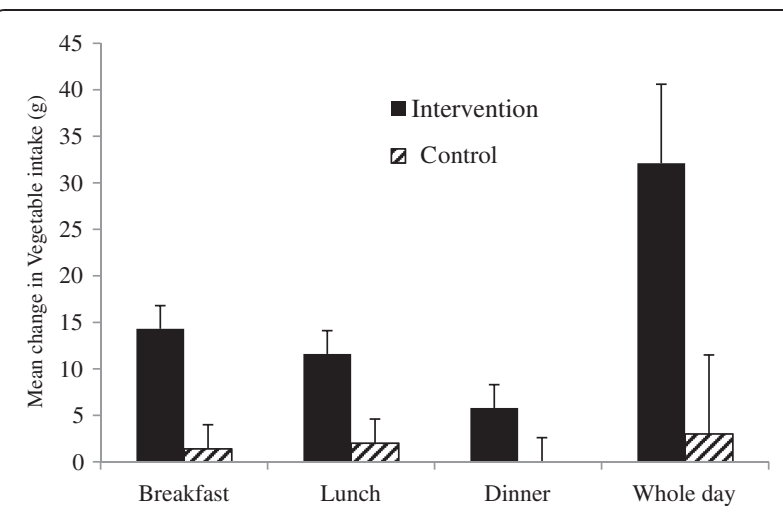

Figure 2 Mean change with standard error at 6 months from baseline in vegetable intake $(g)$.

recommended clinical target for $\mathrm{HbA}_{1 \mathrm{c}}(<6.9 \%)$ [10] was greater in the IG (45\%) than in the CG (29\%).

Although mean changes between the two groups were not significant for BMI, this might be an understandable result considering that 'normal' BMI range for Asians is less than other groups of Europeans and Americans [19,20], and thus are at risk of developing type 2 diabetes patients at a lower BMI. Asking patients who have already reduced total energy intake to some extent, even though not to a sufficient extent, to make further reductions may be not feasible and usually results in low compliance. This is particularly so in patients who are aware of their limitations for weight control or who are not obese and therefore have a moderate energy intake. To change the way of eating at dinner and to recommend eating more vegetables may bring about greater compliance for participants whether or not they are obese. In turn, our dietary education by modifying dietary intake according to meals and encouraging vegetable intake has the probability of being effective in Asian patients who are not obese. In Japan, lifestyle education by registered dietitians for diabetes patients is provided mainly in hospitals and in only a few clinics. Dietary lifestyle education is important for many of type 2 diabetes patients. To conduct a system for effective dietary lifestyle education in clinics should be considered to be warranted in Japan.

\section{Comparison with other studies}

The clinical effectiveness of several medical nutrition therapies for diabetes has been reported [21,22]. Research is increasingly demonstrating that medical nutrition therapy administered by a registered dietitians or nutrition professional is a key component of diabetes management and complements treatment of diabetes by physicians [22]. Considering results from past studies [5,6,16,23-32], it is important for effective glycemic control 1) that patients be given results of nutritional assessments so that meals can be modified $[5,6,16], 2)$ that a registered dietitian provides support to patients in establishing reasonable goals $[5,6,16,23,26,28]$, and 3$)$ that patients be given continuous support in behavior modification [5,6,23-32]. Because medical doctors usually do not have the time for nutritional education, support by co-medical staff members such as registered dietitians is important to bring successful nutritional education to fruition. Actually, several randomized controlled trials examining the effects of long-term lifestyle education by co-medical staff, including dietary education, resulted in success in decreasing $\mathrm{HbA}_{1 \mathrm{c}}$ levels $[6,23,26,27,31]$. Studies [23,27,31] with baseline $\mathrm{HbA}_{1 \mathrm{c}}$ levels (7.3\% to $7.7 \%$ ) similar to ours (7.5\%) showed an effect size for the mean change from baseline of $-0.7 \%,-0.5 \%$, and $-0.1 \%$, respectively, which did not differ largely from our result of $-0.5 \%$.

Because excessive eating at night increases insulin resistance [35], the SILE program aimed to improve FPG by reducing energy intake at dinner and to improve postmeal plasma glucose by increasing vegetable intake at breakfast and lunch and increasing dietary fiber intake. It is known that targeting both postprandial plasma glucose and FPG is an important strategy for achieving optimal glycemic control [36]. The SILE program is characterized as having a target that can be continued by the participant and that would improve both FPG and postprandial plasma glucose levels.

\section{Strengths and limitations of the study}

Studies on lifestyle interventions in individuals with type 2 diabetes have been performed in recent years, including those with individual randomization [5,6,23,24,26-29,31] and cluster randomization designs [25,30,32-34,37,38]. It must be considered that in clinic-based studies there is the possibility of contamination bias between intervention and control participants in the same clinic [39]. Thus, a cluster randomization design would eliminate this possibility. To our knowledge, this is the first cluster randomized study to evaluate structured individual-based lifestyle education in a community setting over a 6-month treatment period in Japan.

To modify behavior with regard to dietary intake, an individualized approach is required in addition to information on appropriate dietary content. In this study, we could review in detail a patient's dietary habits using the FFQW82 and graphs, which helped patients to recognize their nutritional problems and decide what problem-solving and goalsetting strategies could be implemented. This may have successfully resulted in reduced energy intake at dinner and increased vegetable intake at breakfast and lunch and an improvement in the $\mathrm{HbA}_{1 \mathrm{c}}$ level in the IG.

As to whether plasma glucose was more often monitored in the IG than in the CG, there is little possibility of increased monitoring in the IG. In Japan, almost all patients who use insulin are likely to use home glucose 
monitoring, however, the proportions of patients using insulin were similar (around 10\%) in each group, which could eliminate a significant bias.

There are some limitations in this study design. Firstly, only patients were blinded to the assignment of education. In order to avoid selection bias, we asked general practitioners to recruit all the patients in turn. Furthermore, the low number of registered patients in the CG was mainly because of an extended sick leave of a general practitioner in charge of one clinic and the inclusion of a newly started clinic (enrollment of 10 patients, respectively). Therefore, the potential selection bias may be slight.

Secondly, the dropout rates were relatively small; $20 \%$ for the IG and 25\% for the CG. Because our study was based on usual clinical situations, patients were expected to visit their clinics every 2 or 3 months, and we did not anticipate a large number of dropouts. Even though the protocol required enrollment of 10 patients per clinic, we permitted enrollment of 7-13 patients per clinic to allow for dropouts so that statistical power could be maintained and to take into account a shortfall in enrollment in some clinics. Furthermore, we conducted multiple imputation analyses to examine the effect of dropouts on the results.

General practitioners were randomly assigned to either the IG or CG, and general practitioners were permitted to follow their usual clinical practices. Changes in medicines by the participants were not numerous and proportions of these changes were not largely different between the IG and CG $(n=7 ; 7.0 \%$ and $n=11 ; 11.8 \%$, respectively. See Figure 1). We cannot deny the possibility that the general practitioners of patients with less than optimal glycemic control might have changed the diabetes medication of some of these patients during the study period, which would bring about a bias. However, changes in diabetes medication are inevitable in the management of patients with less than optimal glycemic control. In order to examine this point, we added a sensitivity analysis that included 18 patients whose medications were changed during the study period. Thus, PPA included 172 patients (91 [91\%] IG, 81 [87\%] CG). The results were almost concordant with results shown for patients who did not have changes in medication during the study period. In addition, none of the patients used dietary fiber pills as a supplement; however, 4 patients took a tea that was considered a health food to maintain postprandial glucose ( 2 for IG and 2 for CG). This would not seem to affect vegetable intake.

Thirdly, the success of this program was to some degree dependent on the skills of the dietitians involved. To address this issue, we developed a training process for the registered dietitians before the start of the randomization study. Education in implementing the program was therefore important. Furthermore, the assessment sheet with items ranked according to priority helped standardize advice by the registered dietitians. Training for the registered dietitians was conducted based on an instruction manual and thus did not differ between dietitians at the intervention clinics and the control clinics. Although the effects were somewhat varied among the dietitians, the variability among those assigned to the IG and CG was similar. Furthermore, we mentioned that five registered dietitians were in charge of both groups. However, because the dietitians were trained to give advice following the manual, the possibility of contamination of advice was less likely. As for advice on activity, the IG had received more practical advice compared to the CG. In fact, $37 \%$ of the IG responded that they had performed more exercise compared to the CG (17\%). Therefore, not only dietary education but also practical advice on activity might have affected the results. However, our results showed an improvement in dietary intakes, and it is natural to make the interpretation that improvement in dietary intakes resulted in improvements in plasma glucose levels.

Fourthly, in order to improve glycemic control, maintaining long-term control is required. An earlier assessment could be biased as a result of changes made only because subjects were conscious of being studied. The follow-up period in this study was 6 months. However, further study is warranted.

\section{Implication}

In the past, simple lifestyle education for patients with type 2 diabetes was conducted by a general practitioner or clinical nurse in community medical settings while providing medical care. Although dietary education by registered dietitians has been increased by degrees, continuous evidence-based lifestyle education should be warranted. Active utilization of dietitians as co-medical staff can help in successfully providing diabetes care in community medicine. This study provides some evidence for the value of structured individual-based lifestyle education for glycemic control by registered dietitians in primary care settings. The result will be useful to encourage lowering $\mathrm{HbA}_{1 \mathrm{c}}$ and it may help to improve glycemic control not only in Japan but also in other countries.

\section{Conclusions}

The dietitians delivered structured individual-based lifestyle education for glycemic control in primary care settings resulted in significantly improved $\mathrm{HbA}_{1 \mathrm{c}}$ levels in the participants with type 2 diabetes. These results will provide useful information to not only Japanese type 2 diabetes patients but also to other Asian type 2 diabetes patients as well as non-obese type 2 diabetes patients in Western countries. 


\section{Abbreviations}

BMI: Body mass index; CDS: Complete data set; CG: Control group; FPG: Fasting plasma glucose; FFQ: Food frequency questionnaire; FFQW82: Food frequency questionnaire consisting of a list of 82 foods; $\mathrm{HbA}_{1}$ : Hemoglobin $\mathrm{A}_{1}$; IG: Intervention group; ITT: Intention-to-treat; JDS: Japan Diabetes Society; LOCF: Last observation carried forward; MAR: Missing at random; MI: Multiple imputation; NGSP: National Glycohemoglobin Standardization Program; PPA: Per protocol analysis; RCT: Randomized controlled trial; SILE: Structured individual-based lifestyle education.

\section{Competing interests}

The authors declare that they have no competing interests.

\section{Authors' contributions}

MA, KY, MW, MN, EH, and TT conceived and designed the study. IK provided support for medical issue. MA and MW supervised lifestyle education. MA and $K Y$ had full access to all of the data in the study and take responsibility for the integrity of the data and the accuracy of the data analysis. MA, KY, and $\Pi T$ analyzed and interpreted the data and drafted the manuscript. All authors have seen and approved the final version of the paper for publication. $\mathrm{KY}$ and TT provided administrative support and supervised the study.

\section{Acknowledgements}

This study was financially supported by the Ministry of Education, Culture, Sports, Science and Technology in Japan Grant-in-Aid for Scientific Research (C) in 2007-2008 (Grant No. 19500693), 2009-2010 (Grant No. 20175128) (Representative: MW), and The Japan Dietetic Association Grant in 2006 (Representative: MA). The grant had no role in the study design, data collection, data analysis, data interpretation, writing of the manuscript, or decision to submit the manuscript. No potential conflict-of-interest relevant to this article was reported.

\section{Author details}

${ }^{1}$ Nutrition Support Network LLC, 2-2-4 Wakamatu, Sagamihara, Kanagawa 252-0334, Japan. ${ }^{2}$ Teikyo University, Graduate School of Public Health, 2-11-1 Kaga, Itabashi-ku, Tokyo 173-8605, Japan. 3Showa Women's University, Graduate School of Life Science, 1-7 Taishido, Setagaya, Tokyo 154-0004, Japan. ${ }^{4}$ Department of Technology Assessment and Biostatistics, National Institute of Public Health, 2-3-6 Minami, Wako, Saitama 351-0197, Japan. ${ }^{5}$ Kobayashi Medical Clinic, Ryokujukai Cooperation, 5-27-28 Sagamiono, Sagamihara, Kanagawa 252-0303, Japan. ${ }^{6}$ Center for Medical Statistics, SAN Building 401, 2-9-6 Higashi Shinbashi, Minato-ku, Tokyo 105-0021, Japan.

Received: 15 June 2012 Accepted: 6 May 2013

Published: 14 May 2013

\section{References}

1. Danaei G, Finucane MM, Lu Y, Singh GM, Cowan MJ, Paciorek CJ, Lin JK, Farzadfar F, Khang Y-H, Stevens GA, Rao M, Ali MK, Riley LM, Robinson CA, Ezzati M, on behalf of the Global Burden of Metabolic Risk Factors of Chronic Diseases Collaborating Group (Blood Glucose): National, regional, and global trends in fasting plasma glucose since 1980: Systematic analysis of health examination surveys and epidemiological studies with 370 country-years and 2.7 million participants. Lancet 2011, 378:31-40.

2. Danaei G, Lawes CM, Vander Hoorn S, Murray CJ, Ezzati M: Global and regional mortality from ischaemic heart disease and stroke attributable to higher-than-optimum blood glucose concentration: comparative risk assessment. Lancet 2006, 368:1651-1659.

3. National Institute of Health and Nutrition: Outline for the Results of the National Health and Nutrition Survey Japan, 2007. http://www0.nih.go.jp/ eiken/english/research/pdf/nhns2007.pdf.

4. Norris SL, Lau J, Smith SJ, Schmid CH, Engelgau MM: Self-management education for adults with type 2 diabetes: a meta-analysis of the effect on glycemic control. Diabetes Care 2002, 25:1159-1171.

5. Sun J, Wang $Y$, Chen $X$, Chen $Y$, Feng $Y$, Zhang $X$, Pan $Y$, Hu T, Xu J, Du L, Zhou W, Zhao H, Riley RE, Mustad VA: An integrated intervention program to control diabetes in overweight Chinese women and men with type 2 diabetes. Asia Pac J Clin Nutr 2008, 17:514-524.

6. Huang MC, Hsu CC, Wang HS, Shin SJ: Prospective randomized controlled trial to evaluate effectiveness of registered dietitian-led diabetes management on glycemic and diet control in a primary care setting in Taiwan. Diabetes Care 2010, 33:233-239.

7. Morgan L, Hampton S, Gibbs M, Arendt J: Circadian aspects of postprandial metabolism. Chronobiol Int 2003, 20:795-808.

8. Chandalia M, Garg A, Lutjohann D, von Bergmann K, Grundy SM, Brinkley LJ: Beneficial effects of high dietary fiber intake in patients with type 2 diabetes mellitus. N Engl J Med 2000, 342:1392-1398.

9. Adachi M, Yamaoka K, Watanabe M, Tango T: Validity and reproducibility of food frequency questionnaire with 82-food items (FFQW82) for nutrition education. Nippon Koshu Eisei Zasshi 2010, 57:475-485.

10. The Japan Diabetes Society: Evidence-based Practice Guideline for the Treatment of Diabetes in Japan. Tokyo: Nankodo Co., Ltd. Press; 2010.

11. Adachi M, Yamaoka K, Watanabe M, Nishikawa M, Hida E, Kobayashi I, Tango T: Effects of lifestyle education program for type 2 diabetes patients in clinics: study design of a cluster randomized trial. BMC Pub Health 2010, 10:742.

12. Kashiwagi A, Kasuga M, Araki E, Oka Y, Hanafusa T, Ito H, Tominaga M, Oikawa S, Noda M, Kawamura T, Sanke T, Namba M, Hashiramoto M, Sasahara T, Nishio Y, Kuwa K, Ueki K, Takei I, Umemoto M, Murakami M, Yamakado M, Yatomi Y, Ohashi H, Committee on the Standardization of Diabetes Mellitus-Related Laboratory Testing of Japan Diabetes Society (JDS): International clinical harmonization of glycated hemoglobin in Japan: From Japan Diabetes Society to National Glycohemoglobin Standardization Program values. Diabetol Int 2012, 3:8-10.

13. American Dietetic Association: Medical Nutrition Therapy Evidence-Based Guide for Practice: Nutrition Practice Guidelines for Type 1 and Type 2 Diabetes Mellitus. [CD-ROM]. Chicago, IL: American Dietetic Association; 2001.

14. National Diabetes Education Program: 4 Steps to Control Your Diabetes. Bethesda: For Life; 2006. http://ndep.nih.gov/media/NDEP67_4Steps_4c_508.pdf.

15. Society TJD: Evidence-based Practice Guideline for the Treatment of Diabetes in Japan. Tokyo: Nankodo Co., Ltd. Press; 2004

16. Watanabe M, Yamaoak K, Yokotsuka M, Tango T: Randomized controlled trial of a new dietary education program to prevent type 2 diabetes in a high-risk group of Japanese male workers. Diabetes Care 2003, 26:3209-3214.

17. Rubin DB: Multiple Imputation for Nonresponse in Surveys. New York: John Wiley \& Sons, Inc; 1987.

18. Schulz KF, Altman DG, Moher D, the CONSORT Group: CONSORT 2010 Statement: updated guidelines for reporting parallel group randomized trials. BMJ 2010, 340:c332.

19. Sone $\mathrm{H}$, Ito $\mathrm{H}$, Ohashi $Y$, Akanuma $Y$, Yamada $\mathrm{N}$, for the Japan Diabetes Complication Study Group: Obesity and type 2 diabetes in Japanese patients. Lancet 2003, 361:85

20. Nelson KM, Reiber G, Boyko EJ, NHANES III: Diet and exercise among adults with type 2 diabetes: finding from the third national health and nutrition examination survey (NHANES III). Diabetes Care 2002, 25:1722-1728.

21. Pastors JG, Warshaw H, Daly A, Franz M, Kulkarni K: The evidence for the effectiveness of medical nutrition therapy in diabetes management. Diabetes Care 2002, 25:608-613.

22. Morris SF, Wylie-Rosett J: Medical nutrition therapy: A key to diabetes management and prevention. Clin Diabetes 2010, 28:12-18.

23. Deakin TA, Cade JE, Williams R, Greenwood DC: Structured patient education: the Diabetes X-PERT Program makes a difference. Diabet Med 2006, 23:944-954.

24. Hiss RG, Armbruster BA, Gillard ML, McClure LA: Nurse care manager collaboration with community-based physicians providing diabetes dare: A randomized controlled trial. Diabetes Educ 2007, 33:493-502.

25. Trento M, Gamba S, Gentile L, Grassi G, Miselli V, Gabriel M, Passera P, Tonutti L, Tomalino M, Bondonio P, Cavallo F, Massimo Porta, The ROMEO Investigators: Rethink Organization to improve Education and Outcomes (ROMEO): A multicenter randomized trial of lifestyle intervention by group care to manage type 2 diabetes. Diabetes Care 2010, 33:745-747

26. Davis RM, Hitch AD, Salaam MM, Herman WH, Zimmer-Galler IE, Mayer-Davis EJ: TeleHealth improves diabetes self-management in an underserved community: diabetes TeleCare. Diabetes Care 2010, 33:1712-1717.

27. Belalcazar LM, Reboussin DM, Haffner SM, Hoogeveen RC, Kriska AM, Schwenke DC, Tracy RP, Pi-Sunyer FX, Ballantyne CM: The Look AHEAD Research Group: A 1-year lifestyle intervention for weight loss in individuals with type 2 diabetes reduces high C-reactive protein levels and identifies metabolic predictors of change: from the Look AHEAD (Action for Health in Diabetes) study. Diabetes Care 2010, 33:2297-2303 
28. Coppell KJ, Kataoka M, Williams SM, Chisholm AW, Vorgers SM, Mann Jl: Nutritional intervention in patients with type 2 diabetes who are hyperglycemic despite optimized drug treatment-lifestyle over and above drugs in diabetes (LOADD) study: randomized controlled trial. BMJ 2010, 341:C3337.

29. Walker EA, Shmukler C, Ullman R, Blanco E, Scollan-Koliopoulus M, Cohen HW: Results of a successful telephonic intervention to improve diabetes control in urban adults: A randomized trial. Diabetes Care 2011, 34:2-7.

30. Polonsky WH, Fisher L, Schikman CH, Hinnen DA, Parkin CG, Jelsovsky Z, Petersen B, Schweitzer M, Wagner RS: Structured self monitoring of blood glucose significantly reduces A1C levels in poorly controlled, noninsulin-treated type 2 diabetes: results from the Structured Testing Program study. Diabetes Care 2011, 34:262-267.

31. Salinero-Fort MA, Pau ECS, Arrieta-Blanco FJ, Abanades-Herranz JC, Martín- Madrazo C, Rodés-Soldevila B, Rodés-Soldevila B, Burgos-Lunar C: Effectiveness of PRECEDE model for health education on changes and level of control of $\mathrm{HbA}_{1 c}$, blood pressure, lipids, and body mass index in patients with type 2 diabetes mellitus. BMC Publ Health 2011, 11:267.

32. Quinn CC, Shardell MD, Terrin ML, Barr EA, Ballew SH, Gruber-Baldini AL: Cluster-randomized trial of a mobile phone personalized behavioral Intervention for blood glucose control. Diabetes Care 2011, 34:1934-1942.

33. Davies MJ, Heller S, Skinner TC, Campbell MJ, Carey ME, Cradock S, Dallosso HM, Daly H, Doherty Y, Eaton S, Fox C, Oliver L, Rantell K, Rayman G, Khunti K: Effectiveness of the diabetes education and self management for ongoing and newly diagnosed (DESMOND) program for people with newly diagnosed type 2 diabetes: cluster randomized controlled trial. BMJ 2008, 336:491.

34. Goderis G, Borgermans L, Grol R, Broeke CVD, Boland B, Verbeke G, Carbonez A, Mathieu C, Heyrman J: Start improving the quality of care for people with type 2 diabetes through a general practice support program: a cluster randomized trial. Diabetes Res Clin Pract 2010, 88:56-64.

35. Lindsay JR, McKillop AM, Mooney MH, Flatt PR, Bell PM, O'harte FP: Meal-induced 24-hour profile of circulating glycated insulin in type 2 diabetic subjects measured by a novel radioimmunoassay. Metabolism 2003, 52:631-5.

36. Federation TID: 2011 Guideline for Management of Postmeal Glucose. Belgium: Brussels; 2011

37. Sönnichsen AC, Winkler H, Flamm M, Panisch S, Kowatsch P, Klima G, Fürthauer $B$, Weitgasser $R$ : The effectiveness of the Austrian disease management program for type 2 diabetes: a cluster randomized controlled trial. BMC Fam Pract 2010, 11:86.

38. Rubak S, Sandbæk A, Lauritzen T, Borch-Johnsen K, Christensen B: Effect of "motivational interviewing" on quality of care measures in screen detected type 2 diabetes patients: a one year follow up of an RCT, ADDITION Denmark. J Prim Health Care 2011, 29:92-98.

39. Torgerson D: Contamination in trials: is cluster randomization the answer? BMJ 2001, 322:355-357.

doi:10.1186/1471-2458-13-467

Cite this article as: Adachi et al:: Effects of lifestyle education program for type 2 diabetes patients in clinics: a cluster randomized controlled trial. BMC Public Health 2013 13:467.

\section{Submit your next manuscript to BioMed Central and take full advantage of:}

- Convenient online submission

- Thorough peer review

- No space constraints or color figure charges

- Immediate publication on acceptance

- Inclusion in PubMed, CAS, Scopus and Google Scholar

- Research which is freely available for redistribution 